\title{
Acceptance Of Fish Crackers Produced From Tilapia And Catfish.
}

\author{
Okereke A.N And Onunkwo D.N \\ African Regional Aquaculture Centre P.M.B 5122, Port Harcourt/Nigerian Institute For Oceanography And \\ Marine Research, Nigeria/ Michael Okpara University of Agriculture, Umudike \\ nnetina@yahoo.co.uk/donunkwol@gmail.com
}

\begin{abstract}
Sensory Evaluation of fish crackers produced from catfish and tilapia was evaluated in attempt to ensure the possibilities of better utilization of underutilized Tilapia and catfish. The product were produced with corn starch (25\%), pepper (0.1\%) salt $(0.5 \%)$, magi (2 cubes) vegetable oil (18.5\%) Tilapia (35\%), catfish $(35 \%)$.

Tilapia and catfish were deboned using a bone separator and grinded with a pepper grinder and mashed together with $25 \%$ of cornstarch. The mixture was kneaded and moulded into a cylindrical shape and wrapped in a nylon and steamed in a steaming pot for 45 minutes and then put into a refrigeration for 24 hours. The cooled product was cut into shapes and sprayed on the sun for 3 days and deep fried. The acceptance was evaluated with 25 man panel based on taste, flavor, colour and texture and general acceptability.

$75 \%$ of the panelist preferred fish crackers from catfish to those made from tilapia in terms of taste. $85 \%$ like the texture and flavor of the crackers from tilapia than that of catfish. There was higher consumer acceptability for crackers from catfish in terms of taste to that made from Tilapia. There was significant difference observed between crackers from tilapia and catfish. Diversification of fish industry through better utilization of underutilized tilapia and catfish will help to improve commercialization of these products. This will improve food and nutritional security and also help to create a means of revenue generation and alleviate poverty in Nigeria.
\end{abstract}

\section{Introduction}

A large proportion of the total landed fish from tilapia and catfish. most of these fishes have stunted growth and cannot been utilized in this form and they remain unused due to inherent problems related to unattractive color, flavor, texture, small size and high fat content. Most of these species belong to the abundantly available pelagic species, which are by catch, of some unconventional species. (Akande, 1989). Adding fish as nutritional value to staple foods has been researched by many nutrition scientists and food technologists (ANON 2001). Though considerable research has been carried out on the different ways of utilizing small fishes in minced fish production (Akande 1989; Eyo 1999; King 2001).

A variety of fish species are used for fish product, while fish like Alaska Pollock and tropical species such as farmed species like Chineses Carp (Shaviklo 2000). maybe used. The use of fish species with high dark/red muscle and fat content has met with some complication such as how grade protein gel, colour problems and lipid oxidation (Park and Lanier 2000). The production and utilization of fish using locally manufactured pepper grinder (Attrition Mill) was developed by King, M.O of the Nigerian Institute for Oceanography and Marine Research in the processing of ingredients for the preparation of fish cakes, fish burger and fish crackers among others.

The processing yield of Tilapia was reported to be $51 \%$ for dressed fish and $25.4 \%$ for fillet (clement and lovel 1994). Ninan et al., (2010) reported that Tilapia in fresh condition can yield $32-36 \%$ mince. The mince is white in colour, has low fat content and pronounced odour, which makes in an ideal raw material for the preparation of value-added products. There is a great interest in using larger quantities of fish for human food (park and lanier 2000). This will lead to better utilization of the fish species.

The study is aimed at value addition using Tilapia, a low-value fish which at present has limited scope for consumption in fresh form than catfish which is abundant (Ninan et al., 2010). Studies showed that the mince yield of this species is commercial important in the utilization of underutilized species for the production of cutlets, fish balls and cully fish which are simple and cost-effective. Commercialization of these product can contribute to the fish processing industry through better utilization of a relatively underutilized species.

Study Area: The production of fish crackers was done in Nigerian Institute of oceanography and marine research lab. 
Sample Preparation

\section{Materials And Methods}

Fish crackers processing consists of several steps that are described in figure I.

A fresh medium - sized catfish with a length of $30 \pm 35 \mathrm{~cm}$ and a weight of $350 \mathrm{~g}$ and a tilapia with a length of $25 \pm 22 \mathrm{~cm}$ and a weight of $350 \mathrm{~g}$ was purchased from the market in the Lagos state. The deheading and gutting of these species of fish were carried out with knife. Fish flesh was separated from the bones and skin using a bone separator at a low temperature of $20^{\circ} \mathrm{C}$ to minimize the deleterious effect of friction heat on the product Fish flesh was washed thoroughly with running tap. The number of washing cycles and water volume varied with fish species, freshness of fish, type of washing unit and desired quality of the product (Shaviklo 2000).

Tilapia and catfish were deboned when they are fresh and mashed with attrition pepper grinder and mixed thoroughly with $25 \mathrm{~g}$ of corn starch with a cubes of magi, $0.01 \mathrm{~g}$ of pepper, $0.05 \mathrm{~g}$ of salt and then rolled out into cylindrical shape and steam with a steaming pot for $45 \mathrm{mins}$ and cut out with knife into a nice shaped with $1 / 2$ thickness sprayed under sun for 3 day for drying. It is then deep fried in $18.5 \%$ of vegetable oil and then allowed to cool.

\section{PRODUCTION OF FISH CRACKERS FROM TILAPIA AND CATFISH}

The processing method was by frying and the method is described below.

Recipe for production of crackers using tilapia and catfish flesh is in tablel below.

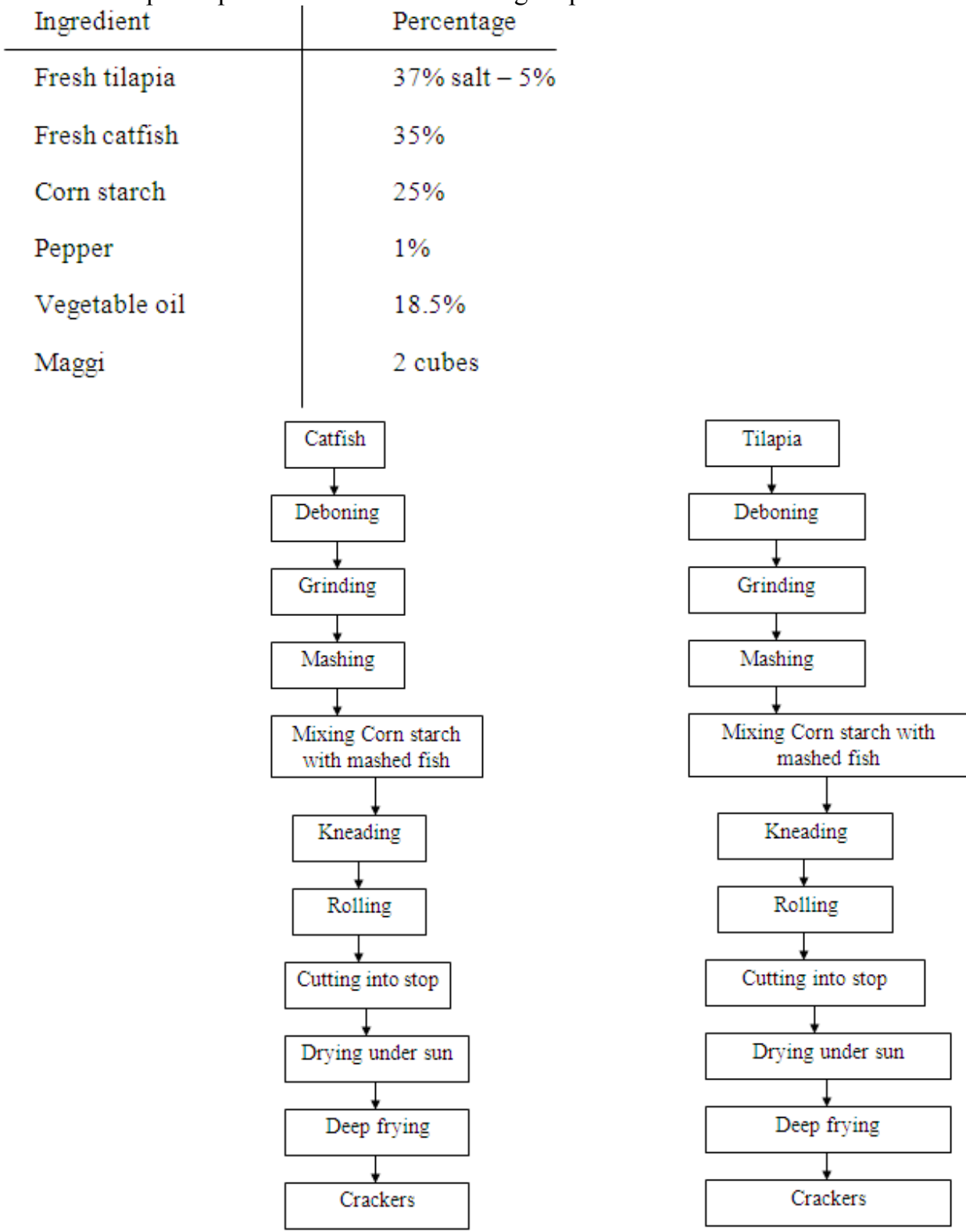

Flow diagram for fish crackers made from catfish. Flow diagram for fish crackers made from tilapia. 
ensure adequate nutrition for all. Food insecurity in sub-Saharan Africa is characterized by widerspread and chronic hunger and malnutrition as well as recurrent and acute food crises.

In this study, there was a higher consumer acceptability of the fish crackers from tilapia. Fish crackers from catfish were more tasty. Products of fish crackers from catfish should be increase to meet the nutritional requirement needed for healthy growth and provide adequate food security for rural community. There was a higher general acceptability of fish crackers from tilapia and catfish so adequate technology should be provided to improve the production of these products and assure food security for rural community. The production of these products will create a means of revenue generation and sustainable development in rural communities and also alleviate poverty.

\section{References}

[1]. Akande, G.A. (1989), Production of Commercially Profitable spiced Minced fish cakes from by catch, Proc. Fourth, Ann. Seminal CODR. Lagos $102-110 \mathrm{P}$

[2]. Anon (2001) What's so healthy about seafood a guide for seafood marketers. Fisheries Research Development Report, Australia.

[3]. Clement S. and Lovell, R.T (1994). Comparison of processing yield and Nutrient Composition of fish Food Journal 17, 245-248

[4]. Eyo, A.A (1999). Storage Potential and Utilization of Tilapia Mince. Proc. $13^{\text {th }}$ Ann.Conf. Fish Soc. of Nig; 135-143P.

[5]. Iwe M.O (2002). Handbook of sensory method and analysis. Ro joint Com. services Ltd Enugu, Nigeria.

[6]. King M.A (2001). A traditional Mill for the Production of Fish Cake. FAO Fisheries Report No. 712. 101-104P Reinccius G. (1990) Off-Flavours on Foods. Critical Reviews in Food Science and Nutrition 29, 381-402.

[7]. Ninan R. Bindu, J. and Joseph J. (2010) Frozen Storage Studies of Value - added Mince-based Products from Tilapia Coreochronis Mossambicus, Peters 1852). Journal of food processing and preservation 34:255-271.

[8]. Park J. and Lanier, T.C (200). Processing of Surimi and Surimi Seafood. In Marine Fresh water Products Handbook; RE Martin Ed; Technamic Publishing Company Lancaster, NH.

[9]. Shavklo G.R (2000). Production Manual of Surimi and Surimi based products Naghsh-emehr Publication Tehran, (in Persian). 